Nr $230 \bullet 1994$

Children's Road Safety and the Strategy of Voluntary Traffic Safety Clubs

Nils Petter Gregersen and Sixten Nolén

Reprint from Accident Analysis \& Prevention, Vol. 26, No. 4, 1994, pp. 463-470

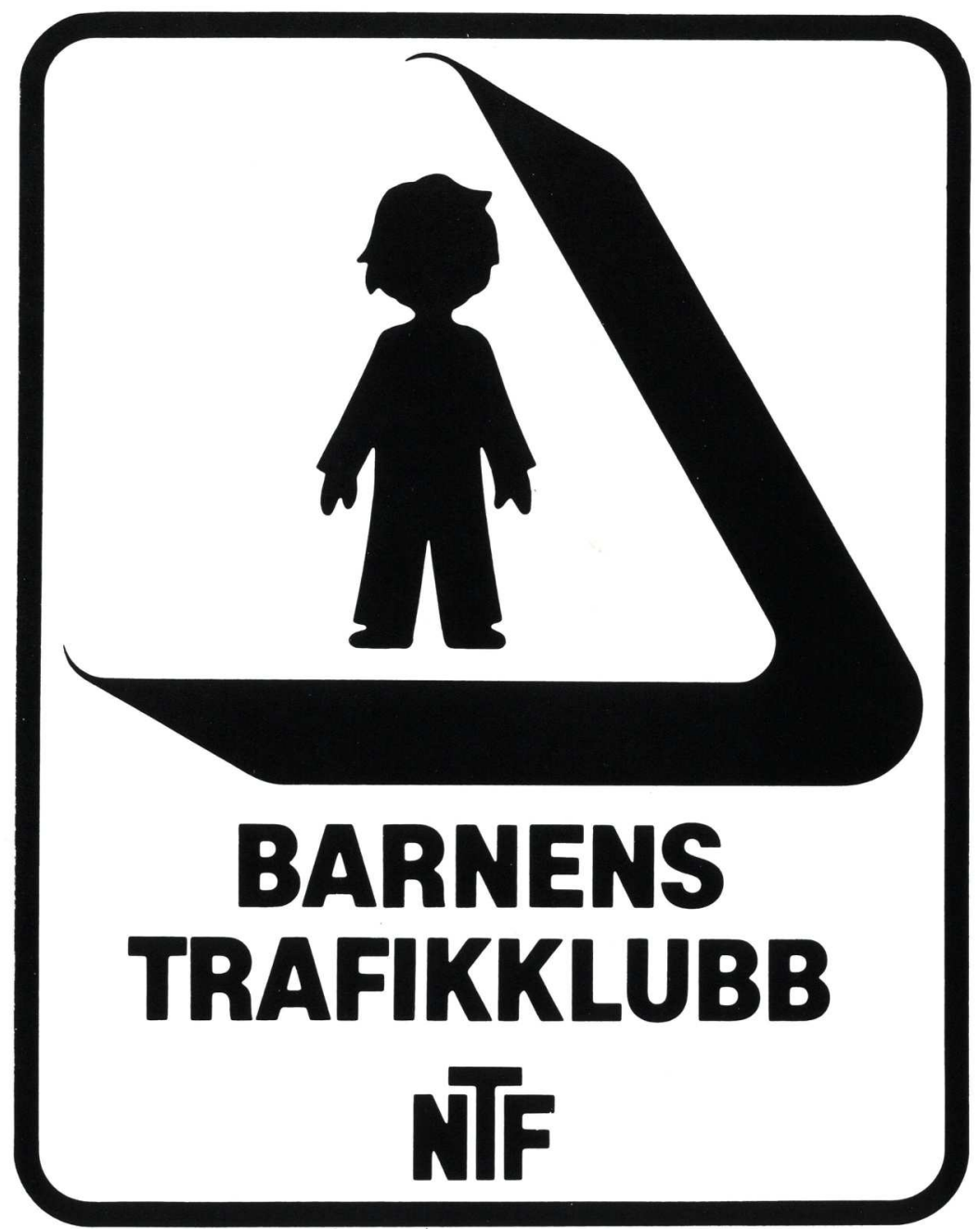

ds 


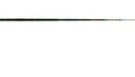




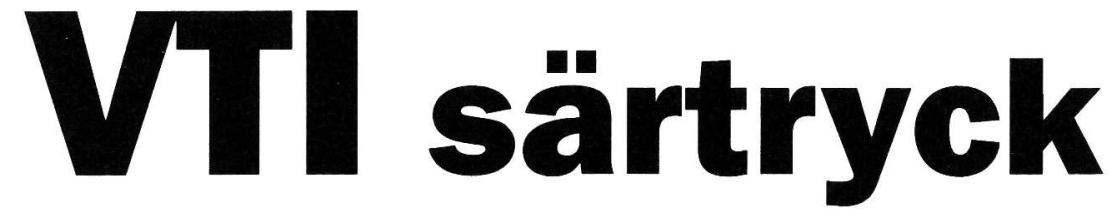

Nr $230 \bullet 1994$

\section{Children's Road Safety and the Strategy of Voluntary Traffic Safety Clubs}

Nils Petter Gregersen and Sixten Nolén

Reprint from Accident Analysis \& Prevention, Vol. 26, No. 4, 1994, pp. 463-470 


\title{
CHILDREN'S ROAD SAFETY AND THE STRATEGY OF VOLUNTARY TRAFFIC SAFETY CLUBS
}

\author{
Nils Petter Gregersen ${ }^{1,2}$ and Sixten Nolén ${ }^{1}$ \\ 'Swedish Road and Transport Research Institute (VTI), S-581 01 Linköping, Sweden, and \\ 'Department of Community Medicine. University of Linköping
}

(Accepted Octoher 1993)

\begin{abstract}
This study focuses on the problem of traffic safety among children and the effectiveness of voluntary traffic clubs. General doubts are growing in regard to this traditional strategy of teaching and training children how to act in specific traffic situations. It has been shown that their knowledge and behavior improve. but the effect on accident risk is not clear. In this study. one model for traditional teaching of this type. a voluntary traffic safety club for children. is evaluated in terms of accident risk. The data have been collected through questionnaires to members and nonmembers of the club. Approximately $20 \%$ of Swedish children are members of the club. The results show that members do not have a lower accident risk than nonmembers. On the contrary, the risk in this nonexperimental study is found to be higher among members. The use of safety equipment is, however, higher among members. The results are discussed in terms of systematic differences between the groups, i.e. socioeconomics, and in terms of the possibility that the general strategy of the club leads to overestimation of the safety effect.
\end{abstract}

\section{INTRODUCTION}

The traffic safety of children is a major problem in most countries. In order to reduce the large number of fatalities and injuries among children, several accident and injury prevention measures are used.

There is no doubt that the injury-preventive effects of protective equipment such as safety belts, child restraints. and bicycle helmets are good. A greater problem is to reduce the number of accidents as such. There are basically three strategies for achieving this. One is to make the traffic environment safer by separating children from dangerous traffic. The second is to make grown-ups realize that children are children and that they can never be made responsible for their behavior in traffic. Consequently, adults must change their own behavior. The third, a more traditional method, is to teach children how to behave safely in traffic.

This third strategy is often used in schools as well as in voluntary safety work. Since this tradition is long-standing and the experience considerable, the method is fairly simple to use. Several studies have shown that practical training of children in real traffic improves their traffic behavior (Roberts 1980; Michon 1981; Van der Mohlen 1983; Rothengatter 1984: Van der Mohlen and Rothengatter 1981). Theoretical teaching of children has been shown to improve their knowledge, but has a limited effect upon behavior (Rothengatter 1981, 1984; Berard-Andersen 1985).

There are, however, growing doubts about the effect of this teaching and training strategy on accident risk. which are based on knowledge from general child psychology. Children are children and can never be expected to assume their own responsibility in traffic. Children have a number of psychological and physiological limitations. They can learn a great deal about how to behave, but they can never be relied on to use their knowledge when necessary (Sandels 1975; Vinje 1981: Rothengatter 1984).

These studies, evaluating teaching and training programs for children, are seldom based upon effects on accident risk. There are no guarantees that effects on knowledge or behavior automatically lead to a reduced accident risk (OECD 1990). The main reasons that accidents are seldom used lie in methodological problems such as small numbers of accidents or a low degree of experimental control (OECD 1983; Rothengatter 1987).

A common method, used in a number of countries, of dealing with this teaching and training of children is through children's traffic clubs, which are voluntary clubs that families join as members. Normally, the strategy in such a club is to offer help to families to fulfil children's teaching and training. In several countries, the principles of the clubs are 
fairly similar to those of the Swedish club (NTF 1986).

In Sweden, the club is organized by the National Society for Road Safety (NTF) and is named the Children's Traffic Club.* This is a members' club for children aged 3-7. It also provides guidance for parents in their work with children to increase road safety. It is mainly focused on the child as a pedestrian. The club therefore supplements the teaching and training in preschools and schools. All children aged three receive an offer to become members. They pay a small fee to join, and every half year they receive in the mail an envelope that includes information and instructions for their parents, work sheets, puzzles, decals, gifts, etc. In all, they receive nine envelopes, each focusing on special themes, such as winter roads, how to cross roads, walking in darkness, etc. Cycling instructions are not included in the Swedish material, because these children are considered too young to ride a bicycle in traffic.

The aims of the Swedish club are to:

1. increase parents' knowledge of children's limited abilities in traffic.

2. implement a continuous teaching and training program to prepare the children for handling different traffic situations as they grow up,

3. create suitable attitudes among children towards traffic.

A general aim of the club is to reduce accident risks in traffic for its members.

However, it is not possible to be sure whether the Swedish club has such risk-reducing effects. The main reason is that no experimental studies of the club have been made. There is a nonexperimental evaluation of the Norwegian club, showing that members have a lower number of accidents than nonmembers, but since the study is nonexperimental, it is difficult to draw definite conclusions. Do the different accident levels between the groups depend on membership or on other systematic differences? (Schioldborg 1974). In nonexperimental evaluations of the English traffic club, The Tufty Club, no improvements in knowledge or behavior were shown (Firth 1973; Antaki, Morris, and Flude 1986). One conclusion that can be drawn from these studies is that membership in traffic clubs is selective. Members have a better socioeconomic situation compared to nonmembers. If a comparison is made of the

\footnotetext{
* The description of the club refers to the situation when the study was made. After the study the club was changed in various ways.
}

accident risk between members and nonmembers in a club, it is not possible to be sure whether differences are explained by membership or by other underlying factors. In a study of child pedestrian injuries in Calgary, Canada, it was clearly shown that more accidents occur in poor neighbourhoods and in areas with high rates of juvenile crime, thus showing that social disadvantages correlate with the number of accidents (Bagley 1992). Similar results were found in an English evaluation (West, Sammon, and West 1993).

This, together with the general doubts about children's capacity discussed above, suggests that an experimental study would be of great importance. Such a study could include three groups to be compared-one experimental group with self-selected, voluntary members; one with children that are persuaded to become members; and a control group of nonmembers.

An experimental study such as this, however, has certain disadvantages. First, it is necessary to persuade a large group to become members, which would probably be an expensive arrangement. Second, it would take several years before the results could be seen. It was therefore decided to conduct a pilot study as preparation for an experimental study.

The hypothesis of this pilot study is that the accident risk is lower among existing members compared to nonmembers. The problem of social selection will probably work in favour of the members, thus increasing this difference even more. If the hypothesis cannot be confirmed, this is a signal that there are problems with the safety effects of the club. These signals ought to be sufficient to start a discussion about the strategy of the club, without conducting the experimental study.

The main purpose of the pilot study was to prepare and test methods, samples, questionnaires, etc., to be used in an experimental study later on.

\section{AIMS}

The primary aim of the study is to investigate whether there are any differences between a group of members in a voluntary traffic club and a group of nonmembers, in terms of accident risk, traffic behavior, and the safety concern of the parents. A further aim is to use the experience and the results from the pilot study in planning an experimental evaluation of this voluntary safety work.

\section{METHODS AND MATERIAL}

The evaluation included three questionnaires sent out by mail on three different occasions. All three were sent to both groups, members and non- 
members. The questionnaires were answered by the parents. The main reason for using three questionnaires was that many of the questions were timerelated, such as number of accidents and degree of exposure. If the time periods for their reports were too long, parents would have had difficulties in remembering details.

The time periods covered by the three questionnaires were as follows: (a) period 1 covered the period October-December 1987 and was sent out in January 1988; (b) period 2 covered the period of January-February 1988 and was sent out in March 1988; (c) period 3 covered the period of March-May 1988 and was sent out in June 1988.

The first two questionnaires were identical. These questions covered mainly traffic accidents and exposure, in traffic as well as in other circumstances. In addition to traffic accidents, there were also questions about other types of accidents. The idea was to create a reference showing whether there were any general differences in accident-proneness, not influenced by membership.

The third questionnaire was more extensive and included, with the exception of the same questions as in the two other questionnaires, more general questions that were not time-related, such as background factors, children's general habits in traffic, use of safety equipment, strategies in traffic teaching and training, and parents' attitudes and beliefs about children in traffic.

The nonmember group was randomly drawn from the Swedish population register (SPAR) and consisted initially of 800 children born in July 1981. By comparing their personal identification numbers with the member register of the club, 229 children who were members were excluded. The nonmember group thus finally consisted of 671 children.

The member group was drawn from the member register of the club. Since there were no routines for randomization in the register, all members born in July 1981 were drawn. The members' group consisted of 1,500 children. In total, 2,171 children received the questionnaires. To reduce the nonresponse rate, two reminders were sent out after each questionnaire. With the same purpose, a lottery was held among those who answered, with five

Table 1. Questionnaire response rates

\begin{tabular}{lccc}
\hline & $\begin{array}{c}\text { Questionnaire } \\
1\end{array}$ & $\begin{array}{c}\text { Questionnaire } \\
2\end{array}$ & $\begin{array}{c}\text { Questionnaire } \\
3\end{array}$ \\
\hline Members & $91 \%$ & $89 \%$ & $86 \%$ \\
Nonmembers & $85 \%$ & $82 \%$ & $76 \%$ \\
Total & $89 \%$ & $87 \%$ & $83 \%$ \\
\hline
\end{tabular}

Table 2. Final size of groups in the pilot study

\begin{tabular}{lccc}
\hline & $\begin{array}{c}\text { Questionnaire } \\
1\end{array}$ & $\begin{array}{c}\text { Questionnaire } \\
2\end{array}$ & $\begin{array}{c}\text { Questionnaire } \\
3\end{array}$ \\
\hline Members & 777 & 761 & 732 \\
Nonmembers & 532 & 518 & 491 \\
Total & 1309 & 1279 & 1223 \\
\hline
\end{tabular}

pocket-size tape recorders and five bicycle helmets as prizes. The response rates are presented in Table 1.

The birth date (July 1981) was chosen since greater effects from the club could be expected the longer the children had been members. The children were about six years of age when they received the questionnaires. By this time, the members had received seven out of nine envelopes from the club.

Membership in the club normally starts at the age of three. It is also possible to become a member at the age of five and thus participate only in the second half of the club. Information on the date of becoming a member was not included in the club register. Because of this, and because of the aim of evaluating the whole club, a question was included in the first questionnaire concerning the date of joining the club. Those who did join at the age of five were excluded from the analysis. Table 2 shows the final size of the groups.

The measure of accident risk used is the number of accidents per 100 hours of exposure. Time is used

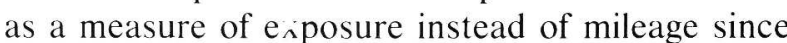
mileage for playing children is impossible to measure. The questionnaire contains a definition of accidents, including injured persons and/or damaged vehicles.

Three different statistical methods were used for testing differences between the two groups. For exposure, the $t$-test was used. For accident risk, the $95 \%$ confidence interval for the quota between the risks of the two groups was calculated. If the confidence interval includes 1.0 , the hypothesis of difference is rejected.

For other comparisons of answers from the questionnaire, chi-square tests were used.

\section{RESULTS}

\section{Comparability between the groups}

One of the basic assumptions that must be confirmed is that the two groups are as nearly equal as possible in aspects other than membership. It is obvious that they are not completely equal, since members voluntarily join the club. To study whether there are any other important differences, questions were asked about certain background factors. No 


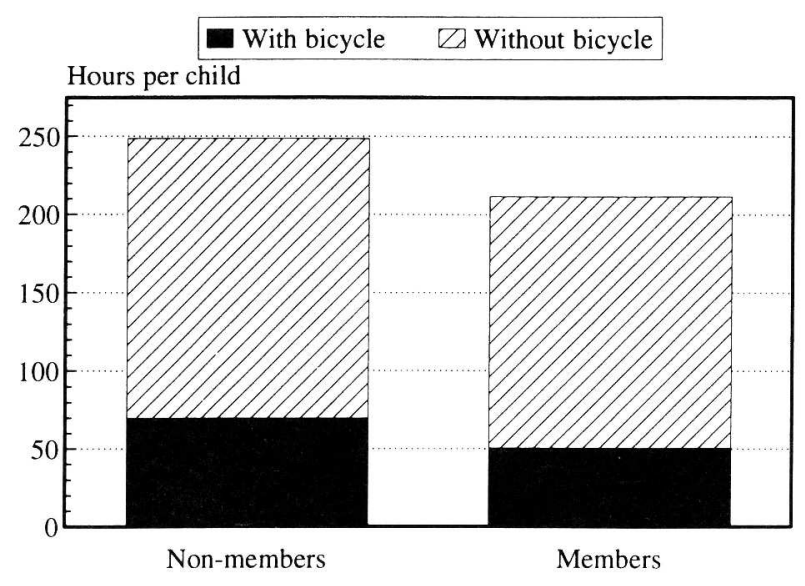

Fig. 1. Exposure measured as hours spent in traffic environments, October-May, with bicycle $(p<0.01)$ and without bicycle (ns).

significant differences were found. The groups do not differ greatly in distribution between the sexes. The distribution among the members is $50 \%-50 \%$ and the nonmembers include $52 \%$ boys and $48 \%$ girls. Most of the families own a car, including $98 \%$ of the member families and $96 \%$ among nonmembers. The same proportion of children in each group, $98 \%$, know how to ride a bicycle.

Car traffic in the neighbourhoods is equally intense. Fifty-eight percent in both groups have either car traffic to and from the house only or no car traffic at all around the house.

\section{Exposure}

The parents estimated the number of hours that the children had been outdoors in traffic environments, riding a bicycle, or walking during the week before they received the questionnaire. Based on this report, the number of hours has been calculated for the whole period of the specific questionnaire.

The results show that the members and nonmembers have been outdoors the same length of time. However, the members have been exposed to traffic environments less than the nonmembers. During the period from October to May, the average time in traffic environments was 210 hours for members and 250 for nonmembers (Fig. 1).

\section{Accident risk}

Comparing the total traffic accident risk (traffic accidents/100 hours) the members have a significantly higher risk. The total number of traffic accidents reported is 394 for members and 162 for nonmembers. If the risk is divided into cycling and noncycling, it is the accident risk when riding a bicycle that is higher among members. Without cycling

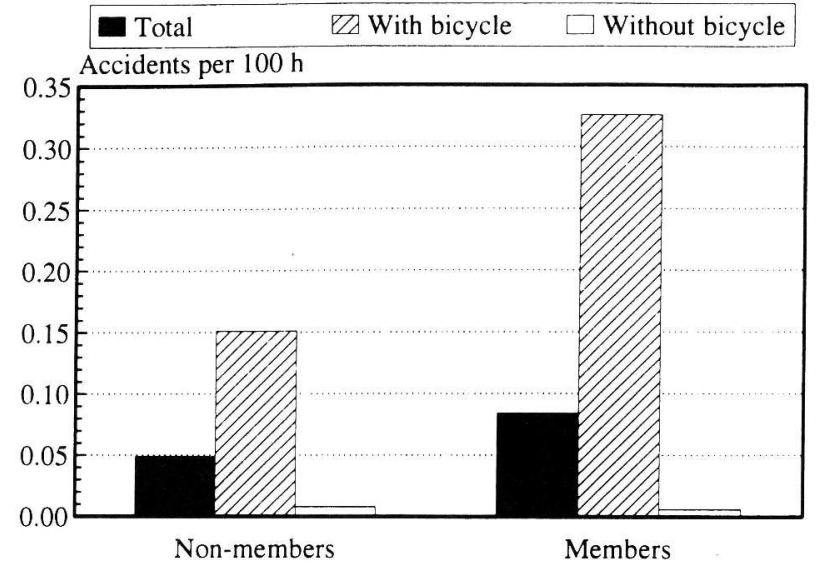

Fig. 2. Traffic accident risks, accidents/100 hours, totally ( $p<$ 0.05 ), with bicycle $(p<0.05)$ and without bicycle (ns).

the number of accidents is very small and no significant differences can be shown (Fig. 2).

Other accidents, excluding traffic accidents, do not show the same difference. There is a tendency to the opposite pattern, with the members having a lower risk (Fig. 3). The number of accidents is low ( 88 for members and 95 for nonmembers). However, the difference is not significant.

The study was not dimensioned to compare the severity of injuries between the groups. The number of severe injuries in the groups was expected to be very low, which it also turned out to be. Therefore no significant differences can be shown in type of injuries. Most of the accidents, 95\%-97\%, are minor; approximately $30 \%$ consist of accidents with vehicle damage only, and $65 \%$ consist of injuries that did not require any hospital treatment.

\section{Freedom of movement}

The parents reported the length of time that the children have spent in traffic environments without

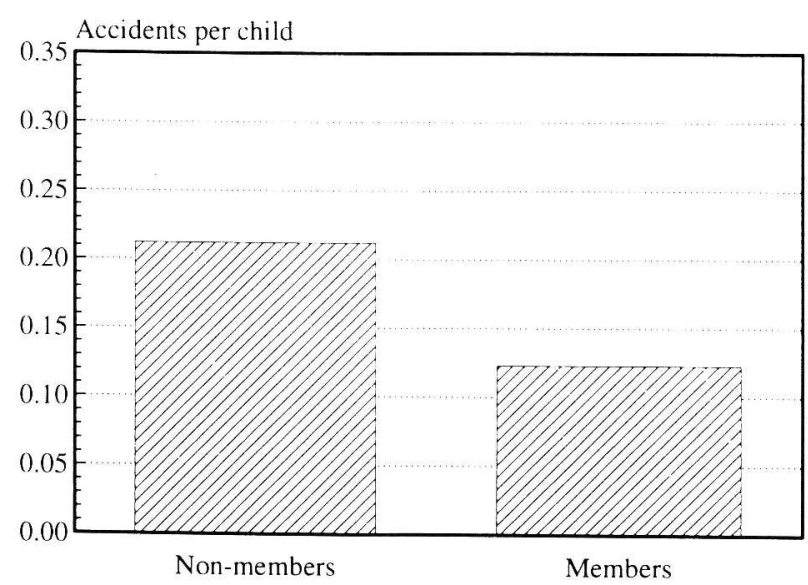

Fig. 3. Accident risk, accidents/child, accidents other than traffic accidents (ns). 


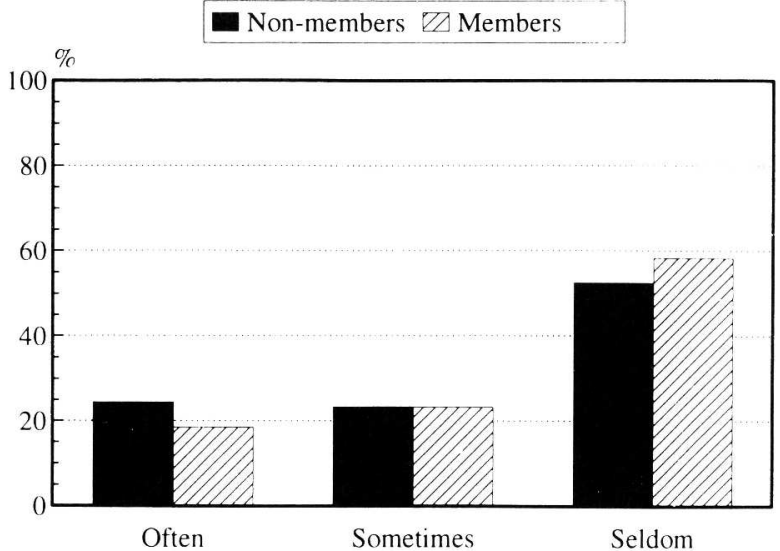

(a)

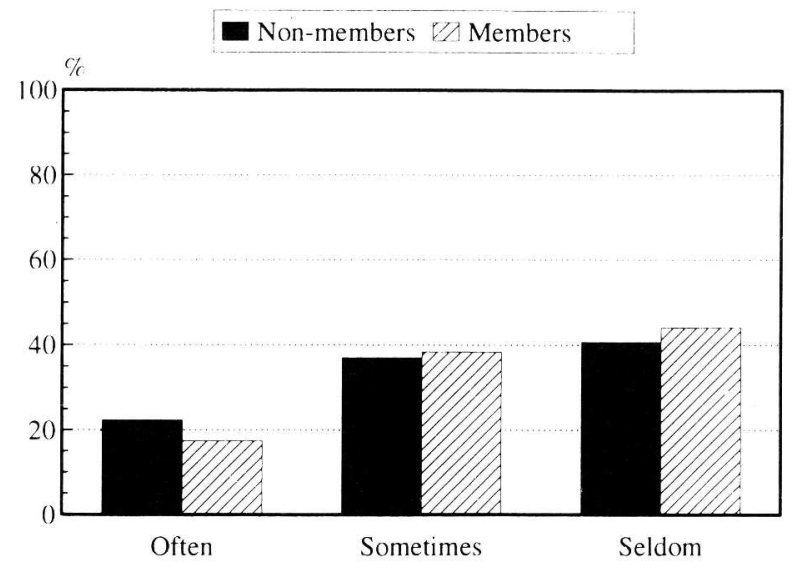

(b)

Fig. 4. Distribution of the children according to how often they are exposed to traffic without a grown-up, (a) as pedestrians ( $p<$ $0.05)$ and (b) when bicycling $(p<0.01)$.

the company of a grown-up. The nonmembers were found to spend a little more time on their own. The difference is significant, but small, for both pedestrians and cyclists (Fig. 4).

\section{Traffic teaching and training}

There is a difference between the number of children in each group who were given teaching and training. A larger number of members were given theoretical teaching $(p<0.001)$ as well as practical training as pedestrians $(p<0.001)$. No difference was found in practical bicycle training (Fig. 5).

The parents were also asked to report how many times they had trained the children in traffic. No significant difference was found in average number of times per child. The questions cover theoretical teaching and practical training as pedestrians as well as cyclists.

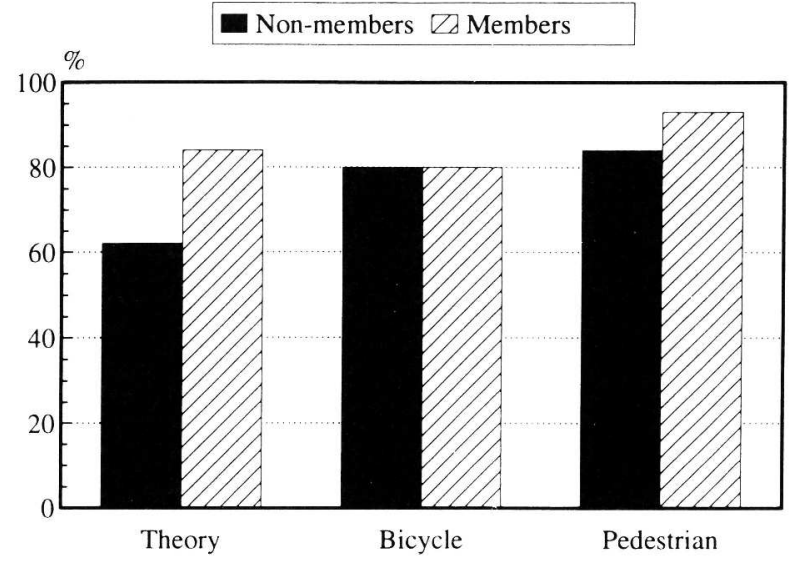

Fig. 5. Percentage of the parents giving their children theoretical teaching $(p<0.001)$ and practical training as pedestrians $(p<$ 0.001 ) and on bicycle (ns).

These results show that if only those children who are given training are compared, the member child receives less training than the nonmember child.

\section{Use of safety equipment}

The members use bicycle helmets and child restraints in cars more often. There is a considerable difference in helmet usage, but concerning the use of child restraints the difference is small. Almost everyone uses child restraints in both groups. No difference was found in the use of reflector tags (Fig. 6).

\section{DISCUSSION}

As mentioned in the introduction, several studies have shown differences between members and

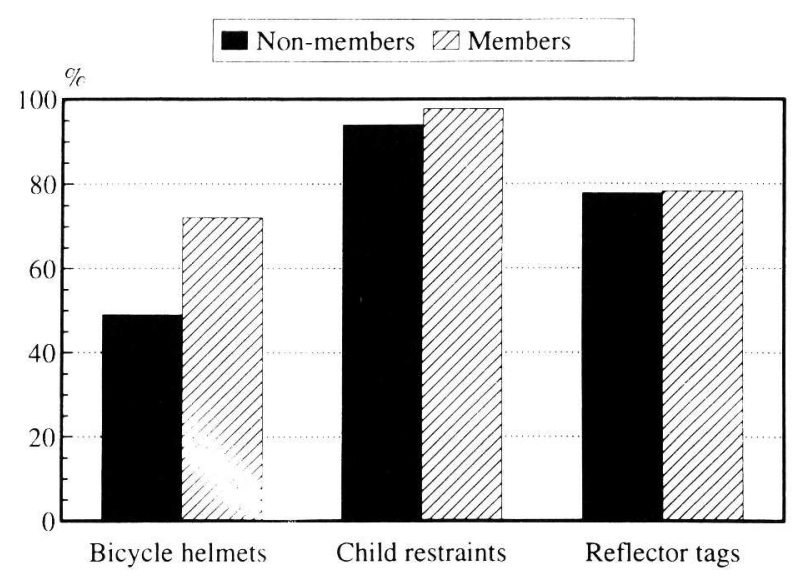

Fig. 6. Percentage of children always or almost always using bicycle helmets $(p<0.05)$, child restraints in cars $(p<0.01)$, and reflector tags (ns). 
nonmembers with respect to socioeconomic circumstances. The member parents are more highly educated, and more of them live in their own houses.

A reasonable conclusion from such findings is that members ought to have a lower accident risk than nonmembers, excluding the effects of the club. The assumption is also supported in this study by the results from accidents other than traffic accidents. In addition, the expectations from the club ought to be a reduction of the accident risk, which would lead to an even larger difference with the members having the lowest risk. However, this can be investigated only in an experimental study.

The results from this study point in a completely opposite direction. There are various results in the study, such as the use of safety equipment and number of parents teaching and training the children, supporting the hypothesis that safety effects are achieved by the traffic club. On the other hand. the results from the comparison of accident risk suggest that the most important effects are negative.

The expected pattern, i.e. a lower risk among members. was found for "other accidents" than traffic accidents, however, the difference is not significant. If this difference is true, it could probathly ho explained by the difference in their socioeconomic background. The difference could be interpreted as a basic level of difference between the groups. show ing how accident-prone they are in general. If this is correct, an experimental study would show an even larger risk for the members in traffic, duc to membership.

Certain other comparisons. not including accident risk, show safer behavior patterns in the member group. The freedom of movement of the members to walk or cycle in traffic alone is lower. The members also spend less time in traffic environments. More of the members also receive traffic teaching and training from their parents, although on a smaller number of occasions per child. There is no difference in the amount of practical training on the bicycle, which could be explained by the fact that the club does not include any training in cycling.

The difference in freedom of movement was expected, since one of the aims of the club is to give parents increased knowledge about children's limited capabilities in traffic. On the other hand, the opposite result might also be expected. Following the second aim of the club, the children should be prepared for handling different traffic situations as they grow up. The second expectation is probably general for traffic education. Children will use their increased ability in their general social development including needs for increased mobility. This is supported by the findings of Nummenmaa et al. (1975).
They found that the freedom of movement did increase as a result of a teaching and training program.

The conclusion is that the results show some safety effects of the club, however, not including the most important aspect; traffic accident risk. The obvious question is whether this is true and what the explanation in that case could be.

Several possible hypothetical explanations to why no reduced accident risk was found may be valid. These explanations are more or less probable if compared to the other results of the study. It is not possible to give any true answers from the study alone, but some of the results may be of help in estimating their probability. There may also be some methodological problems, which will be commented upon first.

One possible methodological explanation for the results is that the member parents are more concerned about matters of children and traffic in general, and are therefore more aware of what is happening to their children. This leads to a more sensitive interpretation of what is to be defined as an accident, which leads to a higher tendency to report minor accidents. This sensitivity may also influence their reports of traffic exposure or the amount of teaching and training.

This risk of overreporting accidents among memhers cannot be ignored, but if this should be the case. it should also be expected that a higher proportion of other, nontraffic accidents would be reported. This is not the case, since these results point in the opposite direction. with a tendency toward fewer "other accidents" in the member group.

Another methodological aspect of over- and underreporting is the consequences of differences between the nonresponse groups. The nonresponse share in the nonmember group is larger than that among members. Hypothetically, this could affect the results and conceal a real accident-reducing effect of the club. In this study, however, it is not very probable, since, if the nonresponse group were to change the results in the opposite direction, there would have to be very large differences between the nonresponse groups. If the nonresponse group among the members had reported no accidents at all and the nonresponse group among the nonmembers had reported a $200 \%$ higher risk than the response group, the results would still not change to the advantage of the members. This kind of error may perhaps reduce the difference between the groups, but never change it to a significantly better accidentreducing effect among members.

One explanation for the unexpected results may be that parents in the member group overestimate the effect of the club, which leads to a greater free- 
dom of movement for the children in traffic or to a higher degree of exposure. However, this assumption is not supported by the results, since it was found that freedom and exposure are lower in the member group.

The overestimation of the skills of the children as road users may, however, also lead to a higher degree of risk taking in traffic. It is not necessarily a matter of quantity, but may be a qualitative aspect of exposure. This cannot be evaluated when measuring the number of hours in traffic, as was done in this study. In general, this type of qualitative difference is very difficult to detect in questionnaires. It is necessary to be there and to study the children's behavior.

Another explanation may be that the children's traffic environment differs between the groups. Neither is this explanation supported by the results, since there were no differences in the proportion of car traffic in the children's immediate environment. Naturally, there may be differences, but in other aspects of the traffic environment not measured in this study.

A possible explanation may also be that membership leads to less teaching and training than the children would have had if they had not become members, because the parents shift the responsibility onto the club. The results may be interpreted this way, since each member child receives less training than a nonmember child. The results show that a similar number of training occasions are distributed over more member children compared to nonmember children.

\section{CONCLUSIONS}

Since these explanations are solely hypothetical and not tested in a controlled experiment, great care should be taken in drawing the conclusion that the effect of the club is negative. Even if several of the results in this study point in that direction, it would be a very drastic conclusion with serious implications, which cannot be drawn from a nonexperimental study such as this.

The probability that there are such great methodological problems in the study that they hide a positive effect is, however, not very high. The differences in socioeconomic background ought to reduce the risk in the member group, not increase it. The risk of nontraffic accidents supports this assumption.

Thus, the most reasonable conclusion from this study is that the club does not have any effect in reducing accident risk.

The results, however, have considerable ethical implications for future club activities in general and for the planned experimental evaluation of the Swedish club. The suggestion for the future is to avoid the planned experimental study, since one of the groups would include children who are persuaded to become members. If this leads to a higher accident risk, which might be the case, such an experiment must be classified as unethical. The results from the pilot study ought to be sufficient to start development of a new strategy for the children's traffic club. The difficult question concerns the direction in which such a change should be made. What strategy should be chosen? This demands more theoretical work and a deeper understanding of the effects of different strategies in traffic safety teaching and training on skills, overestimation, and traffic behavior.

In general, the findings are supported by several other studies of the effects of traffic safety measures. There are many other studies showing unexpected contradictory effects or zero effects of educational measures and other potentially "good" efforts, such as driver education, skid training, training programs for motorcycles, the use of antilock brakes, winter maintenance of roads, the use of studded tyres, etc. (Gregersen 1994; OECD 1990). The number of such studies supporting motivational theories, e.g. zerorisk theory (Näätänen and Summala 1976; Summala 1987 ) is large. These findings ought to lead to greater care in the development of traffic safety measures such as voluntary traffic safety clubs. They also show the importance of evaluating new strategies for safety among children. It often happens that common-sense expectations are found to be unjustified.

The practical result of this study has been a revision of the Swedish "Children's Traffic Club", but this has not yet been evaluated.

Acknowledgements-This rersearch was supported by grants from the National Society for Road Safety (NTF) in Sweden.

\section{REFERENCES}

Antaki, B. C.; Morris, P. E.; Flude, B. M. The effectiveness of the "Tufty Club" in road safety education. Br. J. Educ. Psychol. 56:363-365; 1986.

Bagley, C. The urban setting of juvenile pedestrian injuries: A study of behavioral ecology and social disadvantage. Accid. Anal. Prev. 24:673-678; 1992.

Berard-Andersen, K. Om barn, trafikk og oss voksne. Oslo: Institute of Transport Economics; 1985.

Firth, D. E. The road safety aspects of the Tufty Club. Report LR 604. Crowthorne, U.K.: Transport and Road Research Laboratory (TRRL); 1973.

Gregersen, N. P. Systematic co-operation between traffic schools and parents in driver education, an experiment. Accid. Prev. Anal. 26:453-461; 1994.

Michon, J. A. Traffic education for young pedestrians: An introduction. Accid. Anal. Prev. 13:161-167; 1981. 
Mohlen van der, H. Pedestrian ethology: Unobtrusive observations of child and adult road-crossing behavior in the framework of the development of a child pedestrian training program. The Netherlands: University of Groningen; 1983.

Mohlen van der, H.; Rothengatter, J. A. Road safety education: The development, implementation and evaluation of road safety education programs for children In: European Conference of Ministers of Transport and Council of Europe, Road safety education for children and teenagers. Strasbourg; 1981.

NTF. BTK - now and in the future (in Swedish). BTKgruppen. Stockholm: National Society for Road Safety; 1986.

Nummenmaa, T.; Ruuhilehto, K.; Syvänen, M. Traffic education programme for preschool aged children and children starting school. Report 17. Helsinki: Liikenneturva; 1975.

Näätänen, R.; Summala, H. Road user behaviour and traffic accidents. Amsterdam and New York: North Holland/American Elsevier; 1976.

OECD. Traffic safety of children. Paris: Road Transport Research; 1983

OECD. Behavioural adaptation to changes in the road transport system. Paris: OECD: 1990.

Roberts, M. Appraisal of existing material aimed at teach ing road safety. Report 3/83. Hawthorn, Victoria, Australia: Road Safety and Traffic Authority: 1980.
Rothengatter, J. A. The influence of instructional variables on the effectiveness of traffic education. Accid. Anal. Prev. 13:241-253; 1981.

Rothengatter, J. A. A behavioural approach to improving traffic behaviour of young children. Ergonomics 27:147-160; 1984.

Rothengatter, J. A. Road safety education as accident countermeasure. In: Proceedings of the international workshop Recent developments in road safety research. The Hague: Institute for Road Safety Research (SWOV); 1987.

Sandels, S. Children in Traffic. London: Elek Books Limited; 1975.

Schioldborg, P. Children, traffic and traffic teaching. An analysis of the Children's Traffic Club (in Norwegian). Oslo: Dept of Psychology, University of Oslo; 1974.

Summala, H. Young driver accidents: Risk taking or failure of skills? Alcohol, Drugs and Driving 3:79-89; 1987.

Vinje, M. P. Children as pedestrians: Abilities and limitations. Accid. Anal. Prev. 13:225-240; 1981.

West, R.; Sammons, P.; West, A. Effects of a traffic club on road safety knowledge and self-reported behaviour of young and their parents. Accid. Anal. Prev. 25:609-618; 1993 .

Wilde, G. J. S. The theory of risk homeostasis: Implications for safety and health. Risk Analysis. 2:209-258 1982 . 


\title{
THE RELATIONSHIP BETWEEN TRUCK ACCIDENTS AND GEOMETRIC DESIGN OF ROAD SECTIONS: POISSON VERSUS NEGATIVE BINOMIAL REGRESSIONS
}

\author{
Shaw-Pin Miaou \\ Center for Transportation Analysis, Energy Division, Oak Ridge National Laboratory P.O. Box 2008, \\ MS 6366, Building 5500A, Oak Ridge, TN 37831, U.S.A. \\ (Accepted 25 September 1993)
}

\begin{abstract}
This paper evaluates the performance of Poisson and negative binomial (NB) regression models in establishing the relationship between truck accidents and geometric design of road sections. Three types of models are considered: Poisson regression, zero-inflated Poisson (ZIP) regression, and NB regression. Maximum likelihood (ML) method is used to estimate the unknown parameters of these models. Two other feasible estimators for estimating the dispersion parameter in the NB regression model are also examined: a moment estimator and a regression-based estimator. These models and estimators are evaluated based on their (i) estimated regression parameters, (ii) overall goodness-of-fit, (iii) estimated relative frequency of truck accident involvements across road sections, (iv) sensitivity to the inclusion of short road sections, and (v) estimated total number of truck accident involvements. Data from the Highway Safety Information System are employed to examine the performance of these models in developing such relationships. The evaluation results suggest that the NB regression model estimated using the moment and regression-based methods should be used with caution. Also, under the ML method, the estimated regression parameters from all three models are quite consistent and no particular model outperforms the other two models in terms of the estimated relative frequencies of truck accident involvements across road sections. It is recommended that the Poisson regression model be used as an intial model for developing the relationship. If the overdispersion of accident data is found to be moderate or high, both the NB and ZIP regression models could be explored. Overall, the ZIP regression model appears to be a serious candidate model when data exhibit excess zeros, e.g. due to underreporting. However, the interpretation of the ZIP model can be difficult.
\end{abstract}

Keywords-Truck accidents, Geometric design, Poisson, Zero-inflated Poisson, Negative binomial

\section{INTRODUCTION}

The relationships between vehicle accidents and geometric design of road sections, such as horizontal curvature, vertical grade, lane width, and shoulder width, have been studied using multiple linear regression models in numerous previous studies (Roy Jorgensen Associates, Inc. 1978; Zegeer et al. 1987; Okamoto and Koshi 1989; Zegeer et al. 1990). Because the occurrences of vehicle accidents are typically sporadic across the road network, in most vehicle accidents-geometric design studies the analysts are faced with a problem of dealing with a large number of road sections that had no reported accidents during the observed period. For example, in a study by Zegeer et al. (1990), 55.7\% of the road sections they studied had had no reported vehicle accidents in a five-year period, and in another study by Miaou and Lum (1993b), over $80 \%$ of the road sections had no reported truck accidents during a one-year period. This suggests that for a period of several years most of the road sections considered would have a high probability of being observed with no accidents. In other words, the underlying distribution of the occurrences of vehicle accidents on most of the road sections during the observed period is positively or rightly skewed. It has been demonstrated that the conventional multiple linear regression models. which rely on normal assumption, lack the distributional property necessary to describe adequately the random and discrete vehicle accident events on the road (Jovanis and Chang 1986; Saccomanno and Buyco 1988; Miaou and Lum 1993a). As a result, these linear regression models 




\section{do}

Swedish Road and Transport Research Institute

Forskar för ett liv i rörelse.

Research for an active community.

Statens väg- och transportforskningsinstitut har kompetens och laboratorier för kvalificerade forskningsuppdrag inom transporter och samhällsekonomi, trafiksäkerhet, fordon, miljö samt för byggande, drift och underhåll av vägar och järnvägar.

The Swedish Road and Transport Research Institute has laboratories and know-how for advanced research commissions in transport and welfare economics, road safety, vehicles and the environment. It also has research capabilities for the construction, operation and maintenance of roads and railways.

Adress
Telefon 013 - 204000

Telephone

$+4613204000$
Fax

013 - 141436

Telex 50125 VTISGI S 